\title{
CONSIDERAÇÕES SOBRE AQUISIÇÃO DA LINGUAGEM DE UMA CRIANÇA CIGANA CALON ${ }^{1}$
}

\section{LANGUAGE ACQUISITION OF A GYPSY CHILD FROM CALON ETHNICITY²}

\author{
Marilene Gomes de Sousa Lima ${ }^{3}$ \\ Evangelina Maria Brito de Faria ${ }^{4}$
}

\begin{abstract}
RESUMO: Este trabalho tem como objetivo compreender como uma criança cigana se insere na língua. Para tanto, nos apoiamos na concepção de linguagem, que permeia os estudos bakhtinianos, na qual a língua é dialógica e a forma como se materializa a expressão do psiquismo é multiforme, pois toda expressão pode adquirir valor semiótico na interação. Também recorremos aos estudos sobre a Multimodalidade sustentados por McNeill (2000, 2006) e Kendon (2000), os quais defendem a língua enquanto instância multimodal, em que gesto e produção vocal formam uma única matriz de significação. Nessa mesma direção, o estudo de Kita (2009), que considera a estreita relação entre gesto e cultura. Trata-se de uma pesquisa qualitativa, do tipo estudo de caso. Os dados foram coletados de forma naturalística por um período de oito meses em uma comunidade de ciganos Calon no sertão da Paraíba. Foram gravadas interações naturalísticas de uma criança com idade entre 16 e 24 meses em seu núcleo familiar. Os resultados mostraram que além dos gestos convencionalizados na cultura não-cigana local o gesto emblemático de tocar com a palma da mão no topo da cabeça - usado com o valor semiótico da palavra 'banho' - emerge com e sem produção vocal e a palavra jurin ${ }^{5}$ simultaneamente ao emblema de tocar abaixo da pálpebra inferior com o dedo indicador nas interações entre a díade adulto-criança. Isso evidencia singularidades que perpassam o processo de aquisição da linguagem em culturas ciganas, visto que essa criança cigana Calon ao se inserir na corrente discursiva através da multimodalidade e suas interações são perpassadas por palavras da chibi, que é uma língua compartilhada entre os Calon, e por gestos emblemáticos cujos sentidos são compreendidos entre os membros de sua cultura.
\end{abstract}

PALAVRAS-CHAVE: Aquisição da linguagem. Multimodalidade. Relação gesto-cultura. Criança cigana Calon.

\begin{abstract}
This work aims to understand how a Roma child fits into the language. For this, we rely on the conception of language, which permeates Bakhtinian studies, in which the language is dialogical and the way in which the expression of the psyche is materialized is multiform, since any expression can acquire semiotic value in the interaction. We also resort to studies on Multimodality supported by McNeill $(2000,2006)$ and Kendon (2000), who defend language as a multimodal instance, in which gesture and vocal production form a single matrix of meaning. In the same direction, the study by Kita (2009), which considers the close relationship between gesture and culture. It is a qualitative research, of the case study type. The data were collected in a naturalistic way for a period of eight months in a community of Calon gypsies in the hinterland of Paraíba. Naturalistic interactions of a child aged between 16 and 24 months were recorded in his family. The results showed that in addition to the conventionalized gestures in the local non-gypsy culture, the emblematic gesture of touching with the palm of the hand on the top of the head - used with the semiotic value of the word 'bath' emerges with and without vocal production and the word jurin simultaneously with the emblem of touching below the lower eyelid with the index finger in the interactions between the adult-child dyad. This highlights singularities that permeate the process of language acquisition in gypsy cultures, since this Calon gypsy child inserts himself in the discursive chain through multimodality and his interactions are permeated by words of chibi, which is a language shared among the Calon, and through emblematic gestures whose meanings are understood among the members of their culture
\end{abstract}

\footnotetext{
${ }^{1}$ Agradecemos às famílias de ciganos Calon que atenciosamente têm colaborado com esse estudo. O sentimento é de gratidão pelo compartilhamento de vivências e pela oportunidade de aprendizagem. Obrigada!

${ }^{2}$ We would like to thank the Calon families who have been very helpful in this study. The feeling is one of gratitude for sharing experiences and learning opportunities. Thank you!

3 Mestre e Doutoranda em Línguística pelo Programa de Pós-Graduação em Linguística (PROLING) da Universidade Federal da Paraíba. Participa do Laboratório de Aquisição da Fala e da Escrita -LAFE/UFPB e do Grupo de Pesquisa Linguagem, Enunciação e Interação. ORCID: 0000-0002-4706-4525 E-mail: marilenegomes95@hotmail.com

${ }^{4}$ Profa. Dra. da Universidade Federal da Paraíba, Membro do Proling. ORCID: 0000-0003-2114-1913 E-mail evangelinab.faria@gmail.com

5 Jurin é uma palavra da Chibi, língua compartilhada entre os ciganos Calon.
} 
Volume 14 - Número 2 - ago/dez de 2019

KEYWORDS : Acquisition of language. Multimodality. Gesture-culture relationship. Calon gypsy child.

\section{Considerações iniciais}

Os chamados 'ciganos' estão no Brasil desde aproximadamente o século XVI e há grupos de ciganos de três etnias: Calon, Rom e Sinti, de acordo com Teixeira (2008). Nas palavras de Goldfarb (2010, p. 165), do ponto de vista cultural, os ciganos abrangem "grupos específicos e distintos que se pensam e são pensados como diferentes". No entanto, o fato de serem vistos como 'diferentes' engendra-se no imaginário nacional pautado na existência de uma única cultura cigana e em estereótipos nos quais medra o anticiganismo.

Consideramos que a criança cigana cresce em contexto cultural diferente das crianças não ciganas. Também se pode pensar que a infância dessa criança seja perpassada por um intercruzamento de culturas que vai constituindo sua forma de manifestar o fenômeno da 'ciganidade' - discutido por Shimura (2016) - compartilhado pela sua comunidade. Desse modo, compreendemos que ela cresce em meio a um complexo contexto cultural e, assim, vai se constituindo como sujeitos pela/na linguagem.

Assim, a motivação para realizar esta pesquisa surgiu a partir das seguintes inquietações: Existem particularidades na criança cigana ao se inserir na língua? Será que há pesquisas na área da Aquisição da Linguagem voltadas para esta minoria que está no Brasil desde o século XVI? Que características os enunciados destas crianças apresentam durante o período de aquisição da linguagem?

Diante desses questionamentos realizamos uma busca por estudos sobre a matriz multimodal e culturas ciganas em Aquisição da Linguagem. Buscamos na base de dados de artigos indexados no Portal Periódicos da Capes, no Catálogo de teses e dissertações Capes (Coordenação de Aperfeiçoamento de Pessoal de Nível Superior), na Biblioteca Digital de Teses e Dissertações (BDTD) e na SciELO (Scientific Eletronic Library Online). As palavraschave elencadas para a investigação foram: aquisição da linguagem e criança cigana; multimodalidade e criança cigana; relação gesto/fala e culturas ciganas. Considerado o intervalo de dez anos (2006-2016) notamos que havia na literatura nacional uma lacuna sobre a temática de Aquisição da linguagem e culturas ciganas. Em outros campos do saber como, por exemplo, na Antropologia, alguns estudiosos brasileiros têm se dedicado à temática da criança cigana, a exemplo de Souza e Goldfarb (2012, 2017), Monteiro (2015), Monteiro e Goldfarb (2017); na Educação: Silva (2012), Azevedo e Cardoso (2012). Acreditamos que discutir aquisição da linguagem da criança cigana, além de lhes dar visibilidade, permite que compreendamos melhor sua linguagem, posto que é na e por meio da língua que ela se constitui enquanto sujeito e, torna-se membro ativa em sua cultura cigana local.

Assim, para essa discussão, nos apoiamos na concepção de linguagem, que permeia os estudos bakhtinianos, na qual a língua é dialógica e a forma como se materializa a expressão do psiquismo é multiforme, pois toda expressão pode adquirir valor semiótico na interação. Também recorremos aos estudos sobre a Multimodalidade e nos apoiamos em McNeill (2000, 2006) e Kendon (2000), os quais defendem a língua enquanto instância multimodal, em que gesto e produção vocal formam uma única matriz de significação. Nessa mesma direção, o estudo de Kita (2009), que acrescenta que a há uma estreita relação entre gesto e cultura. Selecionado o arcabouço teórico, pretendemos compreender como uma criança cigana Calon se coloca no discurso, considerando os elementos verbais e gestuais emergentes na dialogia adulto-criança.

Para melhor esclarecer a discussão sobre a entrada dessa criança na língua sob o foco do olhar, dos gestos e da fala, apresentamos, além da exposição teórica, três recortes de 
Volume 14 - Número 2 - ago/dez de 2019

análise, nos quais o gesto emblemático de tocar com a palma da mão no topo da cabeça usado com o valor semiótico da palavra 'banho' - emerge com e sem produção vocal e o gesto emblemático de tocar abaixo da pálpebra inferior com o dedo indicador emerge com a palavra ‘jurin'6 nas interações entre a díade adulto-criança dessa cultura. Vejamos um pouco do embasamento teórico.

\section{Pressupostos teóricos para 'uma compreensão' das interações entre adulto e criança cigana Calon no percurso da aquisição linguagem}

Bakhtin e o Círculo concebem a língua enquanto organismo vivo, dinâmico e, por natureza, dialógico. Nesse sentido, a língua não é tomada como um sistema de categorias gramaticais abstratas, mas "ideologicamente preenchida" Bakhtin ([1975] 2015 p. 40). Essa também é a concepção de língua na qual nos movemos, além de dialogar com os estudos da multimodalidade, mais especificamente nos que discute a relação gesto-fala e sua relação com a cultura no percurso da aquisição da linguagem.

Para Bakhtin/Volochínov (2014, p. 127)7, a verdadeira substância da língua é a interação social por meio da enunciação ou das enunciações. A interação verbal constitui assim a realidade fundamental da língua. Nesse sentido, é preciso compreender que, para além do sistema que perpassa as atividades linguageiras, há todo o contexto dos sujeitos e da situação enunciativa, que se estabelece na interação verbal. Em outras palavras, a realidade fundamental da língua ultrapassa as estruturas linguísticas. Amplia o olhar para ver a unicidade da palavra com o evento, com a situação enunciativa. Assim, as palavras e estruturas sintáticas, uma vez escolhidas e organizadas, produzem enunciados únicos, com uma posição ideológica revelada no aqui e no agora da enunciação.

Para compreender melhor a dialogicidade, conforme aponta Bakhtin (2011), a palavra dita pelo outro vai aos poucos se tornando nossa palavra, não apenas a palavra com sua neutralidade, mas a palavra carregada de tom valorativo, dita pelo outro que interage e que marca seu lugar social. Ao pensar dentro do processo de aquisição da linguagem, aquilo que o referido autor cita enquanto 'processo de assimilação' pode ser refletido também colocando em foco a criança que aprende de seus familiares no âmbito das interações. Assim, nessa inter-relação a criança traz para seu discurso não a palavra da língua com toda sua neutralidade, mas sim a palavra desse 'outro' que está sempre carregada de expressividade e com posição ideológica marcada. Podemos ver essa ação quando a criança incorpora o próprio nome produzido pela mãe com carinho, novas palavras de forma lúdica ao ser convidada a completar palavras em um jogo incessante de trocas e na produção de textos pragmaticamente adequados.

Para Bakhtin/Volochínov (2014, p. 117), o produto da interação são os enunciados. Os interlocutores, seres socialmente organizados, estabelecem diálogo através de enunciados que estão sempre marcados pela situação social. Esses enunciados, que são dirigidos sempre a alguém, são sempre modelados levando em consideração o outro a quem a palavra será dirigida.

Segundo Del Ré, Paula \& Mendonça (2014), os trabalhos dos franceses Frédéric François (1993, 1994, 2004, 2006) e Salazar-Orvig (1999, 2003), entre outros, são pioneiros em tratar das ideias elaboradas por Bakhtin e o Círculo como sendo importantes para se refletir sobre a aquisição da linguagem com vistas à compreensão do funcionamento da linguagem humana. Tomar as ideias propostas por Bakhtin e o Círculo e trazê-las para refletir

\footnotetext{
${ }^{6}$ Jurin é uma palavra da Chibi, língua compartilhada entre os ciganos Calon.

${ }^{7}$ Embora a autoria de Marxismo e Filosofia de linguagem seja atribuída a Volochínov, estamos respeitando a assinatura presente na edição utilizada.
} 
sobre a entrada da criança na linguagem é, nas palavras de Del Ré, Paula e Mendonça (2014, p. 19) "[...] compreender a linguagem da criança e esta como sujeito que enuncia e que, ao enunciar, habita o mundo com voz própria". Tal compreensão torna-se o alicerce para conceber que a "linguagem, a língua e a fala não são entidades abstratas, mas enunciados (concretos), ditos por sujeitos, que por meio deles, constituem-se e também constituem um modo de habitar o mundo".

Nessa direção, é posta em evidência a criança enquanto sujeito social, histórico e situado, ativo e responsivo e a língua enquanto processo de interação. Para nós, essa é a chave para compreender os enunciados proferidos pelas crianças no percurso do processo da aquisição da linguagem e na constituição de sua identidade. De fato, a produção vocal infantil revela muito além da estrutura da língua que lhe é apresentada e, é dentro dessa perspectiva, que podemos compreender a interação adulto-criança Calon e ver através dos enunciados como esse infante vai se tornando competente do ponto de vista de como faz uso da linguagem para interagir nas diversas esferas discursivas.

Cavalcante e Naslavsky (2011) afirmam que, desde o momento de seu nascimento, o bebê já é considerado como um sujeito dialógico por parte do adulto. Através da fala atribuída ao bebê pela mãe nota-se esta estrutura dialógica, uma vez que a mãe desloca seu discurso e se pronuncia como se fosse o próprio bebê quem estivesse falando, considerando, dessa forma, um parceiro dialógico mesmo antes desse pronunciar alguma palavra em sua língua materna. É no diálogo que a criança vai se constituindo enquanto sujeito, através do manhês, esta modalização vocal que marca a prosódia e um lugar discursivo para o infante.

A respeito disso, Del Ré, Paula e Mendonça (2014) propõem que a criança vai se constituindo nessas relações dialógicas. As relações cotidianas fomentam a construção da identidade sendo esta de caráter dialógico.

Sobre essas relações, perpassadas pela linguagem, Ávila-Nóbrega (2010) ressalta que, dentro dos estudos que investigam a interação entre mãe e criança em período de aquisição da linguagem, as produções vocais e verbais ganhavam destaque nas análises. Contudo, faz-se necessário compreender que, analisando a interação dentro de um plano multimodal, outros aspectos tais como gestos e olhar também compõem os enunciados. As primeiras elaborações linguísticas produzidas por bebês são significativas e não se pode priorizar nenhuma hierarquia de fenômenos como: balbucios, holófrases e gestos dentro do processo de aquisição da linguagem. Concordamos com essa afirmação e acrescentamos que toda expressão pode adquirir valor semiótico na interação entre sujeitos, conforme ressalta Bakhtin/Volochínov (2014).

Ainda que a obra de Bakhtin e o Círculo tenha tocado nessa questão, mesmo sem mencionar a palavra 'multimodalidade' compreendemos que muitos dos seus escritos contemplam e valorizam o estatuto multimodal da(s) língua(s) que circulam na sociedade. Poderíamos, inclusive, trazer alguns dos fragmentos para discutir. No entanto, optamos por trazer as vozes de outros autores que têm se dedicado ao estudo dos gestos, inclusive propondo algumas nomenclaturas e aprofundamentos específicos. Fazemos o que o próprio Círculo se propunha: a abertura para dialogar com as 'fronteiras'.

Assim sendo, sustentamos que a comunicação face a face em humanos é uma atividade multimodal que envolve vários elementos (Holler et al., 2014). Dessa forma, conceber língua enquanto instância multimodal é entender que não só na produção vocal repousam os significados, outros elementos, como postura corporal, expressões faciais, olhar, bem como gestos, carregam significação nas trocas comunicativas. Embora todos estes elementos sejam passíveis de análise, estarão sob enfoque, neste trabalho, os gestos como um dos planos multimodais na composição do enunciado.

Kendon (2000) afirma que gesto e a fala são componentes de um único plano. Partindo de uma perspectiva semiótica, esse autor argumenta que é por meio da parceria entre o gesto e 
fala que os enunciados alcançam significado em interações na quais os participantes estão presentes. Algumas peculiaridades dos gestos são apresentadas, a saber, uma de suas utilidades é que eles podem acrescentar significado em um enunciado, podem tornar o contexto verbal mais preciso e, por isso, são complementares.

McNeill (1985) defende que o funcionamento da língua é sempre multimodal. Assim, há uma integração entre gesto e fala e ambos compõem uma única matriz de produção e significação. $\mathrm{O}$ fato de a gesticulação emergir durante as produções vocais aponta para a ideia de que há uma coordenação de dois tipos de pensamento: o imagístico e o sintático (MCNEILL, 1985).

Segundo McNeill (2006), Kendon (1982) propôs uma classificação para os gestos, uma gradação de um continuum, nomeado mais tardiamente por McNeill (1992) por Kendon's Continuum para gesticulação, emblemas, pantomimas e a língua de sinais, organizados conforme o quadro abaixo:

Quadro 01 - Kendon's Continuum

\begin{tabular}{|c|c|c|c|c|}
\hline & Gesticulação & Pantomimas & Emblemas & Língua de Sinais \\
\hline Continuum 1 & $\begin{array}{c}\text { Presença } \\
\text { obrigatória de fala }\end{array}$ & Ausência de fala & $\begin{array}{c}\text { Presença opcional } \\
\text { de fala }\end{array}$ & Ausência de fala \\
\hline Continuum 2 & $\begin{array}{c}\text { Ausência de } \\
\text { propriedades } \\
\text { linguísticas }\end{array}$ & $\begin{array}{c}\text { Ausência de } \\
\text { propriedades } \\
\text { linguísticas }\end{array}$ & $\begin{array}{c}\text { Presença de } \\
\text { algumas } \\
\text { propriedades } \\
\text { linguísticas }\end{array}$ & $\begin{array}{c}\text { Presença de } \\
\text { propriedades } \\
\text { linguísticas }\end{array}$ \\
\hline Continuum 3 & Não convencional & Não convencional & $\begin{array}{c}\text { Parcialmente } \\
\text { convencional }\end{array}$ & $\begin{array}{c}\text { Totalmente } \\
\text { convencional }\end{array}$ \\
\hline Continuum 4 & Global e sintética & Global e analítica & $\begin{array}{c}\text { Segmentada e } \\
\text { analítica }\end{array}$ & $\begin{array}{c}\text { Segmentada e } \\
\text { analítica }\end{array}$ \\
\hline
\end{tabular}

Fonte: Elaborado com base em McNeill 2000, p. 5-10.

Assim, na organização, quatro contínuos foram formulados de acordo com algumas características relacionais, a saber: O Continuum 01 trata dos gestos e sua relação com a fala, o Continuum 02 diz respeito as suas propriedades linguísticas, já o Continuum 03 informa sobre a relação gesto-convenção, por fim, o Continuum 04 trata da relação do caráter semiótico.

Com relação à gesticulação, diz-se que é o movimento que acompanha a fala sendo comum seu uso em todas as línguas. Realiza-se, em geral, usando os braços e as mãos, porém, não se restringe ao uso apenas dessas partes do corpo (MCNEILL, 2006).

Os emblemas são sinais convencionalizados numa determinada cultura, assim, podem variar quanto à forma e conteúdo de expressão. Ao emergirem na ausência de fala, ainda se nota que carregam o significado que lhe fora convencionalizado. Outro detalhe é que os emblemas têm raízes históricas tão profundas quanto às da língua na qual ocorrem (MCNEILL, 2006). Com relação aos gestos emblemáticos e aquisição da linguagem, ÁvilaNóbrega (2010) propôs que gestos como 'dar e 'receber', 'estender a mão para solicitar um objeto', 'apontar', 'estender a mão para mostrar algo ao parceiro', 'chamar outrem com a mão' também são gestos emblemáticos no percurso da aquisição da linguagem.

As pantomimas se configuram enquanto gestos ou sequência de gestos que formam uma narrativa de uma ação cotidiana sem presença de fala. Atenta-se para a questão desse conceito ter sido adquirido através de estudos com adulto. Como revisa Cavalcante (2012), na fase aquisicional, as pantomimas ocorrem também com presença de produção vocal no locus interativo mãe-bebê. Sustenta-se que a fala da mãe atrelada ao gesto pantomímico garante o reconhecimento sócio-histórico do gênero discursivo em questão.

Por fim, as línguas de sinais. Nestas, os sinais se apresentam em substituição da produção vocal, apresentando estrutura linguística própria, tais como padrões gramaticais, 
acervo lexical, padrões morfológicos etc. (MCNEILL, 2006). É importante ressaltar que, segundo Gesser (2009), as línguas de sinais, assim como qualquer língua oral, apresentam-se com variações linguísticas que são motivadas pelos mesmos fatores (sociais, econômicos, geográficos) que ocasionam variações nas línguas orais.

Ainda sobre a multimodalidade, Souza e Faria (2010, p. 138), ao citarem KerbratOrecchioni (1990), enquadram os gestos como linguagem não verbal que "permeia todos os enunciados verbais em tamanha concordância (...), que os elementos verbais e não verbais formam um continnum, já que no curso da interação ambos os elementos podem se encontrar e funcionar em harmonia". Para estas autoras, todo gesto realizado traz algo a ser comunicado, visto que se constitui a partir de uma ação comunicativa (p. 137). E, quando citam Morato (2004), acrescentam que não existe ação ideologicamente nula, visto que toda ação acontece em um quadro social e, sendo assim, estão submetidas às "normas de gestão histórico-cultural". Nessa perspectiva, os gestos estabelecem uma relação direta com o meio social, no qual se está inserido.

Kita (2009) aprofunda essa relação gesto-cultura. Para o autor, o fato de nos expressarmos através fala é universal e cultural. Então, não é de se admirar que, até os tempos hodiernos, não nos deparamos com o relato da existência de uma cultura na qual não haja coexistência de fala e gestos. Porém, dada esta universalidade, a forma como os gestos se materializam, no discurso, pode variar entre culturas. Diante da diversidade cultural dos povos, é natural uma variação semiótica. Assim, várias culturas podem ter gestos com uma mesma configuração, porém com significado diferente, bem como numa perspectiva intracultural, um mesmo gesto pode significar ter diferentes significados.

Kita (2009) elabora uma revisão sistemática na qual reúne trabalhos de diversos estudiosos que tratam sobre a relação gesto-cultura. O agrupamento destas pesquisas o levou a delimitar pelo menos quatro fatores que influenciam a variação transcultural dos gestos. São eles: convenção, específico de cada cultura, para associações de forma-significado; cognição espacial específico de cada cultura; diferenças linguísticas, uma vez que idiomas têm diferentes recursos lexicais e sintáticos, e a pragmática gestual específica de cada cultura. Vejamos na figura a seguir:

Figura 01: Fatores que regem a variação dos gestos

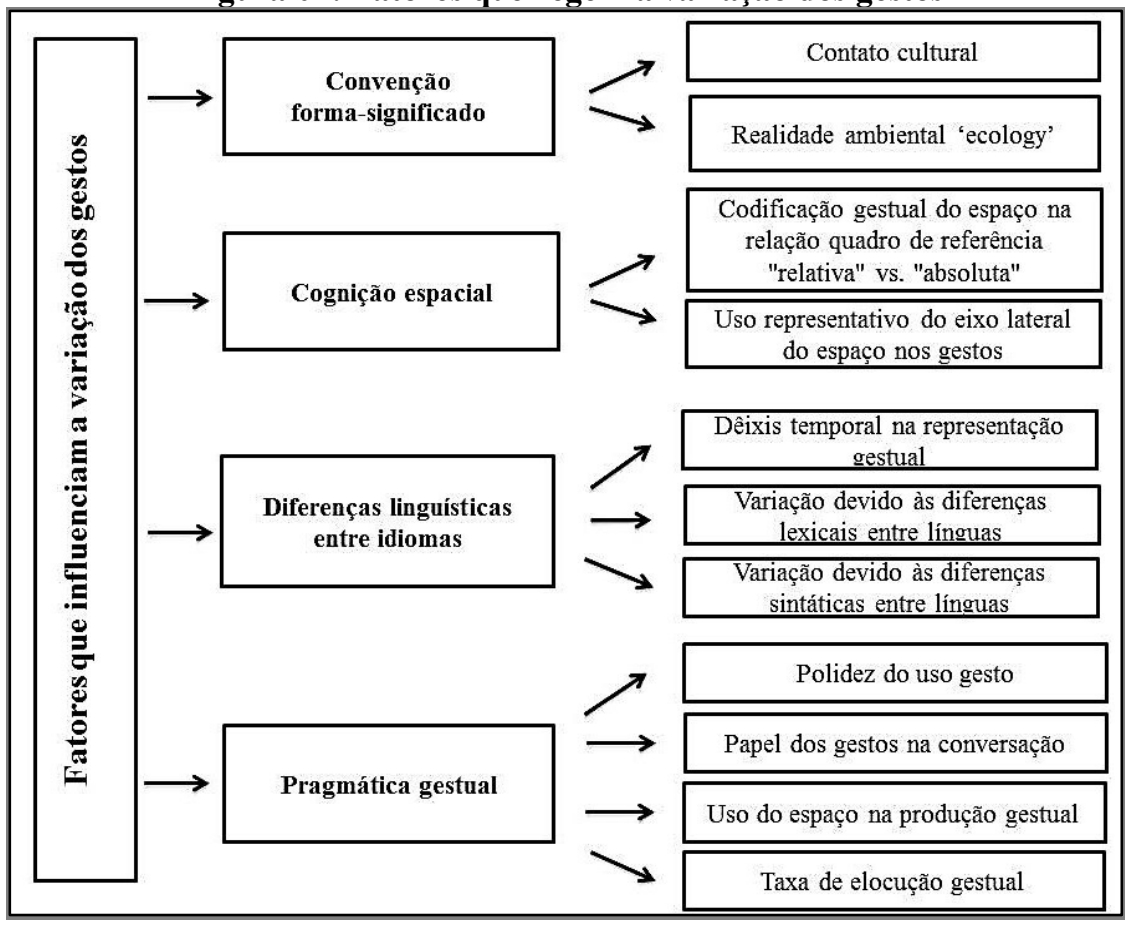

Fonte: Lima (2017). Com Base em Kita (2009). 
Volume 14 - Número 2 - ago/dez de 2019

Sobre a convenção forma-significado, ao citar os estudos de Brosnahan e Okada (1990), Calbris (1990), Creider, (1977) Kendon (1992, 2004), Morris, et al. (1979), Kita (2009) ressalta que as pesquisas direcionadas à relação gesto-cultura destacam que cada cultura tem um conjunto distinto de gestos convencionalizados. Salienta-se que, pelo fato de a forma e o significado dos emblemas estarem relacionados por convenções de uma cultura específica, a relação torna-se muitas vezes opaca, ou seja, não é compreendida por membros de outras culturas (CALBRIS, 1990; KITA, 2009). Por exemplo, Sutherland (1975) notou um gesto peculiar entre as mulheres de etnia rom lowara: elas tocam os seios umas das outras em um gesto de cumprimento depois de certa ausência. Este mesmo gesto repete-se para mostrar apreciação a uma história engraçada ou um gracejo. Fonseca (1996) notou o mesmo gesto em uma mulher cigana na Albânia. Campos (1999) realizou uma pesquisa etnográfica com alguns ciganos no Rio de Janeiro e constatou o elevado número de gestos usados em interações. Esses poucos relatos são uma evidência de que eles possuem um repertório de gestos culturalmente marcados.

Acerca da diferença na cognição espacial, Pedersonet, et al. (1998) afirmam que informação espacial é compreendida de forma diferente entre as culturas. Assim, definiu-se, através de experimentos, que a codificação linguística de uma cultura está diretamente relacionada à forma como os falantes compreendem e representam noções espaciais em tarefas linguísticas e não-linguísticas. Assim, há culturas nas quais os falantes usam o quadro de referência relativa (a relação espacial é dada mediante a localização de seu corpo, como por exemplo 'a minha direita/esquerda' ou 'na minha frente/costas', já outras culturas que fazem uso de um quadro de referência baseado na relação absoluta e tomam como ponto de referências os pontos cardeais 'norte/sul/leste/oeste'. Por exemplo, falantes de línguas europeias modernas, como o inglês, usam o quadro relativo de referência como representação espacial, já outras culturas, a exemplo dos falantes de línguas australianas como o 'arrernte' usam o quadro de referência absoluto, pois em sua língua não há palavra equivalente para os termos 'direita/esquerda'. Assim, o uso dos gestos reflete diretamente nesta forma de compreender o espaço.

Sobre as diferenças linguísticas entre idiomas, Kita (2009) destaca um terceiro fator que influencia a variação intercultural dos gestos. Este está diretamente ligado às diferenças linguísticas, uma vez que idiomas têm diferentes recursos lexicais e sintáticos. Assim, verificou-se que a forma como o enunciado se organiza sintaticamente e os recursos lexicais disponíveis e selecionados influenciam, de forma direta, a produção gestual. Kita e Özyürek (2003) pesquisaram sobre as diferenças na coordenação de gesto e fala em diferentes línguas (turco, japonês e inglês) e concluíram que a diferença nos recursos lexicais entre línguas geram variação na representação gestual. Tal resultado enfatiza, ainda mais, a noção de que gesto e fala estão inter-relacionados e formam uma matriz de significação.

Por fim, no quarto fator Kita (2009) propõe uma 'pragmática gestual' com quatro desdobramentos: polidez gestual, papel dos gestos na interação, uso do espaço na produção gestual e a taxa gestual como aspectos regidos pela diversidade cultural.

A figura 01 mostra, além dos quatro fatores, alguns desdobramentos que a revisão sistemática de Kita (2009) apresenta. Movemo-nos dentro do primeiro fator 'Convenção forma-significado' mais especificamente centramos na realidade ambiental. Concordamos que cada cultura tem um conjunto distinto de gestos convencionalizados e em nossa compreensão, estes quatro fatores abarcam, assim, outros possíveis desdobramentos. No entanto, em se tratando dessa ubíqua relação é preciso enfatizar que essas diferenças se revelam ainda mais importantes se compreendidas além de sua imanência, sendo necessário considerar uma reflexão sobre o caráter ideológico, posto que “[...] Entonando e gesticulando, o homem 
ocupa uma posição social ativa com respeito a certos valores determinados pelas mesmas condições de sua existência social" (VOLOCHÍNOV, 2013 [1926], p. 85).

Em linhas gerais, reconhecer a língua como multimodal é admitir que gestos dos mais variados tipos estabelecem um papel na produção de sentido durante a interação entre interlocutores. Quando se compreende a criança enquanto alguém que enuncia, que deseja interagir com outrem e que a relação entre adulto e criança é dialógica cabe observar como se dá esta interação dentro do Envelope Multimodal $^{8}$ quando a criança ainda não domina a estrutura morfossintática da língua materna, tendo em vista que está em um processo de aquisição. É com esse ajuste de 'lentes' que buscaremos uma compreensão dos enunciados que compõem a interação entre a díade adulto-criança cigana de etnia Calon no percurso da aquisição da linguagem.

\section{Uma criança cigana Calon na língua}

No Brasil, há grupos de ciganos destas três etnias (Calón, Rom e Sinti). A historiografia demonstra que, durante o reinado de Dom João V (de 1706 a 1750), a coroa portuguesa adotou algumas políticas "anti-ciganas". O que é consenso é o fato de que foi de Portugal que vieram os primeiros ciganos ao Brasil. Isto ainda no século XVI, em 1574. A grande maioria não veio de livre e espontânea vontade, mas forçados, expulsos da metrópole ibérica (TEIXEIRA, 2008).

No período colonial, a considerada "natureza nômade" dos ciganos foi por vezes involuntariamente executada, fato este que colaborou com a dispersão destes grupos étnicos por toda a extensão do território brasileiro. Teixeira (2008, p. 19) descreve esses deslocamentos forçados como uma "política do mantenha-os em movimento".

Além disso, ressalta-se que a coroa portuguesa, em um decreto datado de 11 de abril de 1718 escrito por Dom João, quando do degredo de alguns ciganos ao Estado da Bahia, ordenou que os ciganos que chegassem ao Brasil fossem proibidos de falar e ensinar seu idioma aos seus filhos, com vistas a sua extinção (MORAES FILHO, 1981).

Sob estes tipos de opressão e preconceito, o povo cigano foi crescendo em número e espalhando-se pelos Estados do território brasileiro. Entre esses, no Estado da Paraíba concentra um número considerável de ciganos Calon. De acordo com as etnografias já realizadas há ciganos em cerca de dezoitos cidades na Paraíba (MONTEIRO, 2015), dentre essas, Sousa registra um número considerável de ciganos de etnia Calon.

Em Sousa-PB os Calon falam português brasileiro e Chibi de Calon. A 'parada para morar' se deu, de fato, por volta da década de 80 . Goldfarb (2013, p. 181) aponta que, enquanto grupo, os ciganos de Sousa-PB se reconhecem como distintos e apresentam, dentre alguns traços distintivos, sua língua como um importante símbolo de pertencimento a uma identidade, de uma legitimação de origem, de "Signo de enraizamento e de pertencimento ao grupo" uma vez que, tal signo "permite que conectem códigos e valores que antecedem o "tempo de atrás". Assim, a língua situa-se no interstício das origens das representações sociais que os grupos têm sobre si, em oposição à sociedade envolvente [...]".

Foi nesse contexto que coletamos dados naturalísticos de interação de uma criança entre 16 e 24 meses em seu seio familiar por um período de oito meses entre julho de 2015 e março de 2016. Através de uma análise qualitativa de três fragmentos, ilustramos e convidamos o leitor a compreender e refletir sobre a entrada dessa criança cigana Calon na língua por meio da matriz gesto-fala, levando em consideração as singularidades, sua

\footnotetext{
${ }^{8}$ Nomenclatura proposta por Ávila-Nóbrega (2010) para se referir à composição 'olhar-gestos-fala'.

${ }^{9}$ Para uma melhor compreensão da coleta de dados e análise quantitativa ver Lima (2017).
} 
Volume 14 - Número 2 - ago/dez de 2019

subjetividade acessível através da língua permeada pela cultura que compartilha com seus pares.

Salientamos que este estudo seguiu a normativa da Resolução 466/2012 e Norma operacional 001/2013 que aborda pesquisas com seres humanos. Para tanto, o referido estudo foi enviado para a apreciação do Comitê de Ética e Pesquisa do Centro de Ciências da Saúde da Universidade Federal da Paraíba (CEP-CCS). O projeto foi aprovado por unanimidade por este referido comitê técnico e assim codificado: CAAE 51565815.8.0000.5188

Para análise e transcrição dos dados, contamos com o programa ELAN (Eudico Language Annotator), disponível no site do Max Planck Institute for Psycholinguistics. Este software admite, para além da visualização, transcrições, bem como exportação de observações sistemáticas dos dados audiovisuais. Nele criamos trilhas para gestos, olhar e produção vocal dos interactantes no intento de observarmos a emergência de uma instância dialógica e multimodal de língua. As transcrições foram organizadas seguindo a proposta de 'Envelope Multimodal' (EM) de Ávila-Nóbrega (2010), que contempla olhar, gestos e produção vocal na composição da interação. Para as transcrições de produção vocal, usamos chaves $*\{\}^{*}$, colchetes $*[]^{*}$ para os gestos e parênteses $*()^{*}$ para o direcionamento do olhar dos interactantes.

Os recortes foram feitos levando em consideração o lócus das cenas de atenção conjunta, que segundo Tomasello (2003, p. 135) são "interações sociais nas quais a criança e o adulto prestam conjuntamente atenção a uma terceira coisa, e à atenção um do outro à terceira coisa, por um período razoável de tempo". Consideramos estas cenas como um espaço privilegiado para olharmos o funcionamento multimodal da interação. No entanto, não nos deteremos em classificá-las ${ }^{10}$ nas análises que seguem. Vejamos o primeiro extrato:

\section{Extrato 01}

Situação: Mãe e criança brincando no chão da garagem da casa dos pais Idade da criança: 17 meses e 06 dias

\section{CRIANÇA (olha para os bombons)}

MÃE \{quem deu o bombom? quem deu o bombom a tu?\} (alterna o olhar entre os brinquedos e a criança)

\section{CRIANÇA}

MÃE

CRIANÇA

MÃE
$\{$ in:: $\}$ (alterna o olhar entre os brinquedos e os bombons) \{eim?\} (olha para a criança)

\{in:: \} (Olha para a criança) [aponta em direção a sua pálpebra inferior] (olha para a pesquisadora)

\{foi a jurin foi? risos\} [aponta em direção a sua pálpebra inferior] (olha para a pesquisadora e depois para a criança)

${ }^{10}$ Um detalhamento sobre estes aspectos pode ser visto em Lima (2017). 
Volume 14 - Número 2 - ago/dez de 2019

Figura 02: Interface do contexto interativo do extrato 01

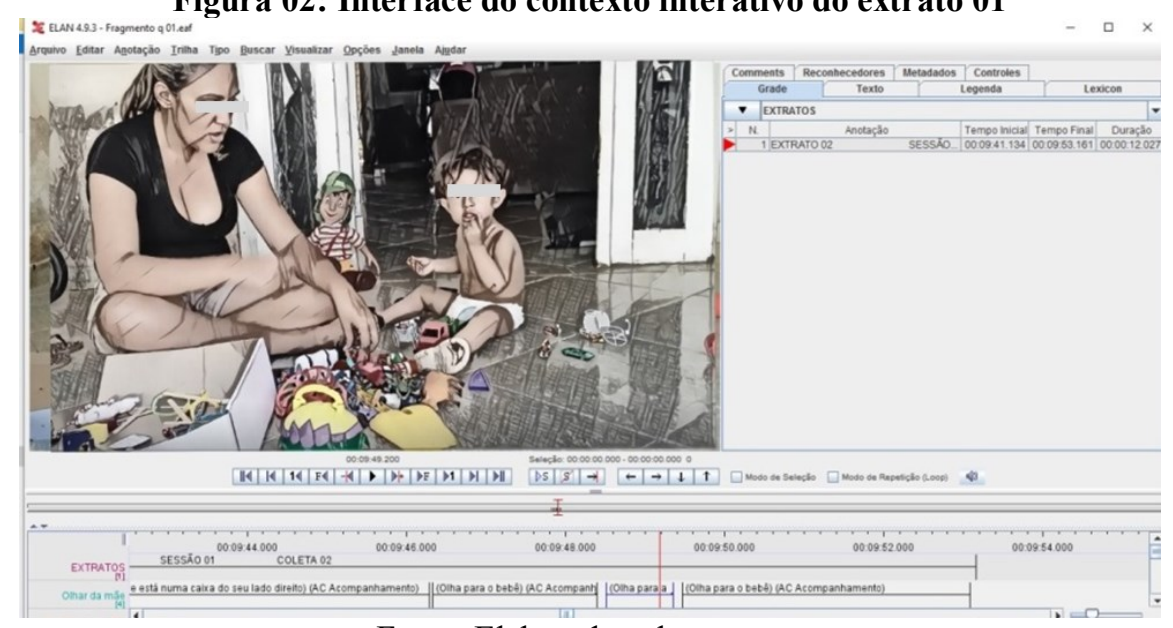

Fonte: Elaborada pelas autoras

Por meio desse recorte compreendemos que a interação entre mãe e criança é sustentada por enunciados compostos pelo olhar, gestos e produções vocais que instauram sentidos compartilhados entre os interactantes. Para além dos gestos de apontar convencional, esse recorte traz particularidades na matriz multimodal que perpassam a entrada dessa criança na linguagem conforme os turnos linhas 03 e 05 . No turno 03 enquanto dirige o olhar da mãe para a pesquisadora, a criança lança mão do enunciado 'in' que é um recorte da palavra 'jurin' que em chibi de calon significa mulher não-cigana. Já no turno 05 simultaneamente ao recorte dessa palavra a criança realiza o gesto emblemático realizado com a mão configurada em forma de apontar convencional e dedo indicador tocando a pálpebra inferior. A figura a seguir evidencia a execução desse gesto emblemático:

Figura 03: Execução do gesto emblemático juron/jurin/juren pela díade

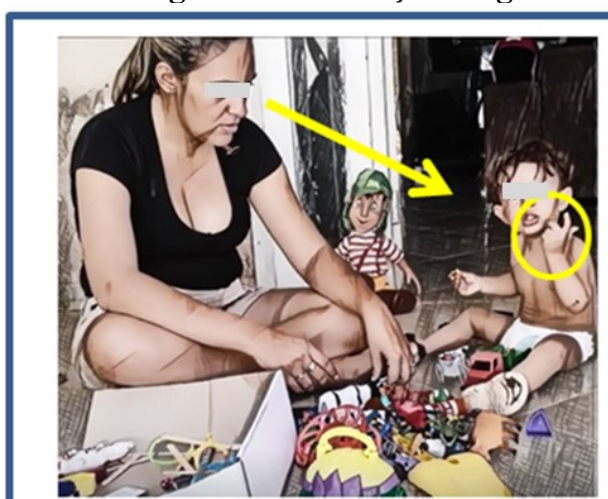

(1)

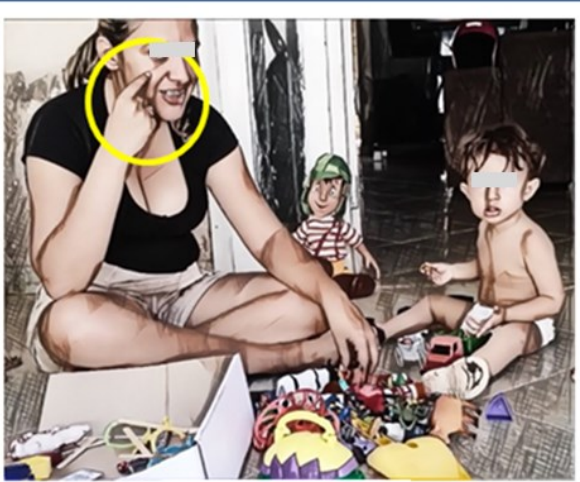

(2)

Fonte: Elaborada pelas autoras

Para além dos outros gestos que emergiram na cena, o emblema que ocorre concomitantemente às produções vocais 'in' e 'jurin' da criança e da mãe respectivamente têm forma e conteúdo partilhado pelos membros da comunidade cigana $\mathrm{Calon}^{11}$ na qual essa família está inserida. Só compreendemos essa matriz porque, ao término da filmagem a mãe, ciente dos objetivos da pesquisa, compartilhou o conteúdo do gesto realizado pelo bebê e reforçado por ela. Na ausência dessa informação seria impossível compreender os sentidos

\footnotetext{
11 Restringimos à comunidade cigana Calon em Sousa-PB porque não sabemos se esse mesmo gesto é compactuado em outras comunidades ciganas espalhadas no território nacional, nem como tal gesto foi convecionalizado ou como chegou à comunidade na qual realizamos a coleta.
} 
partilhados durante esta interação corroborando, assim, com Kita (2009, p. 146) quando discorre sobre a relação entre gesto e cultura e explicita que "a forma e o significado dos emblemas estão relacionados por convenções de uma cultura específica, a relação é muitas vezes opaca para membros de outras culturas".

Tanto a singularidade da produção vocal quanto do gesto emblemático co-ocorrem para a construção do que chamos aqui do 'ser-Calon'. Essa matriz se constitui com mesmo status do gesto de apontar, pois, ao se materializar, indica que há, naquele espaço, um/a não cigano/a, demarcando, assim, uma posição em relação a esse 'outro'. A mãe também é o 'outro' da criança, que, por meio da linguagem, sustenta a interação, que insere a criança em contextos nos quais fomenta o aprendizado dessa identidade Calon que é constituída na base da alteridade. Vemos uma marca de constituição do cigano Calon, em relação a esse 'outro' que não pertence ao seu grupo sendo construída na interação entre mãe e criança.

\section{Extrato 02}

Situação: A criança estava interagindo com a mãe, quando essa lhe mostra o primo e a avó materna que carregam água do poço até a área externa da casa. A criança afasta-se da mãe e passa a interagir com seu primo.

Idade da criança: 17 meses e 27 dias

$\begin{array}{ll}\text { CRIANÇA } & \begin{array}{l}\text { \{ca\} (olha para o primo) [chama com a mão e em seguida } \\ \text { estende a mão para o primo] } \\ \text { Pcom o balde?\} (olha para a criança) [estende a mão e em }\end{array} \\ \text { PRIMO } & \begin{array}{l}\text { seguida segura na mão da criança] } \\ \text { (olha para a pesquisadora) }\end{array} \\ \text { CRIANÇA } & \begin{array}{l}\text { \{ê:: }\} \text { [toca duas ou mais vezes com a palma da mão no ponto } \\ \text { mais alto da cabeça] (olha para o balde de água, em seguida } \\ \text { CRIANÇA }\end{array} \\ & \begin{array}{l}\text { para o primo e retorna a olhar para o balde) } \\ \text { tomar banho?\} (olha para a criança) }\end{array}\end{array}$

Figura 04: Interface do contexto interativo do extrato 02

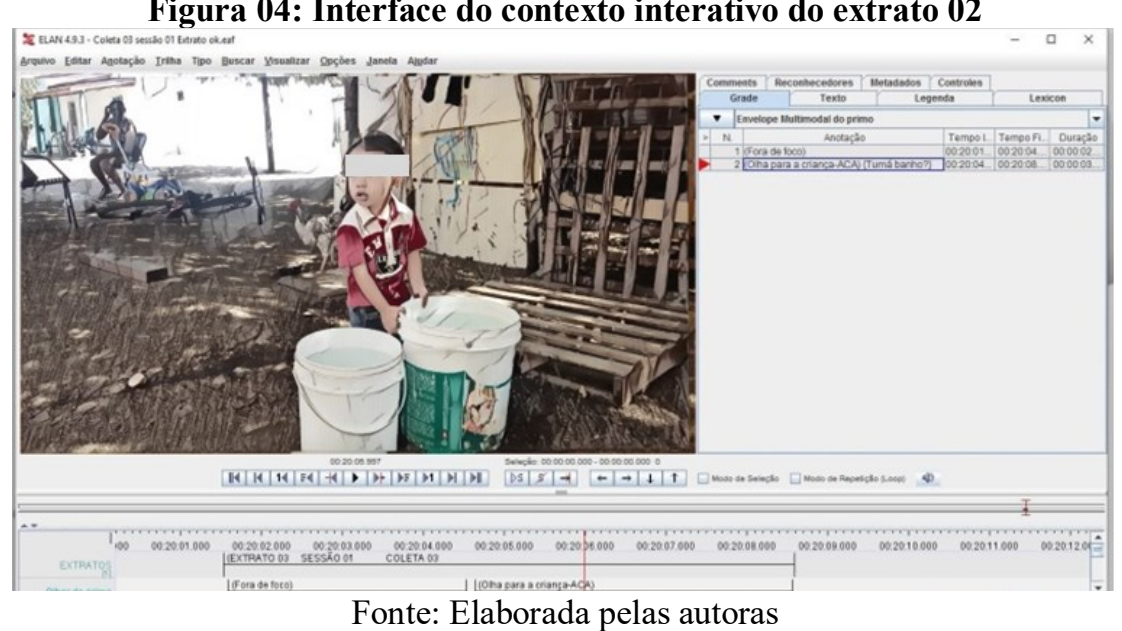

Esse extrato enfatiza novamente funcionamento multimodal da língua, conforme McNeill (1985). A particularidade da cena ocorre, como podemos ver no turno 05 do Envelope Multimodal dos interlocutores, quando esta, após estabelecer um olhar de checagem com a pesquisadora, retorna a olhar para o primo e, nesse momento da cena, faz um gesto emblemático (realizado de forma a tocar duas ou mais vezes com a palma da mão na parte mais alta da cabeça) simultaneamente ao balbucio ' $\hat{E}$ '. Por se tratar de um emblema, tem seu 
sentido compartilhado entre os ciganos Calon em Sousa-PB e, por conseguinte, muitas vezes é opaco para os membros de outras culturas, conforme Kita (2009). A figura a seguir mostra algumas fases e a configuração desse gesto:

Figura 04: Fases do gesto emblemático 'banho'

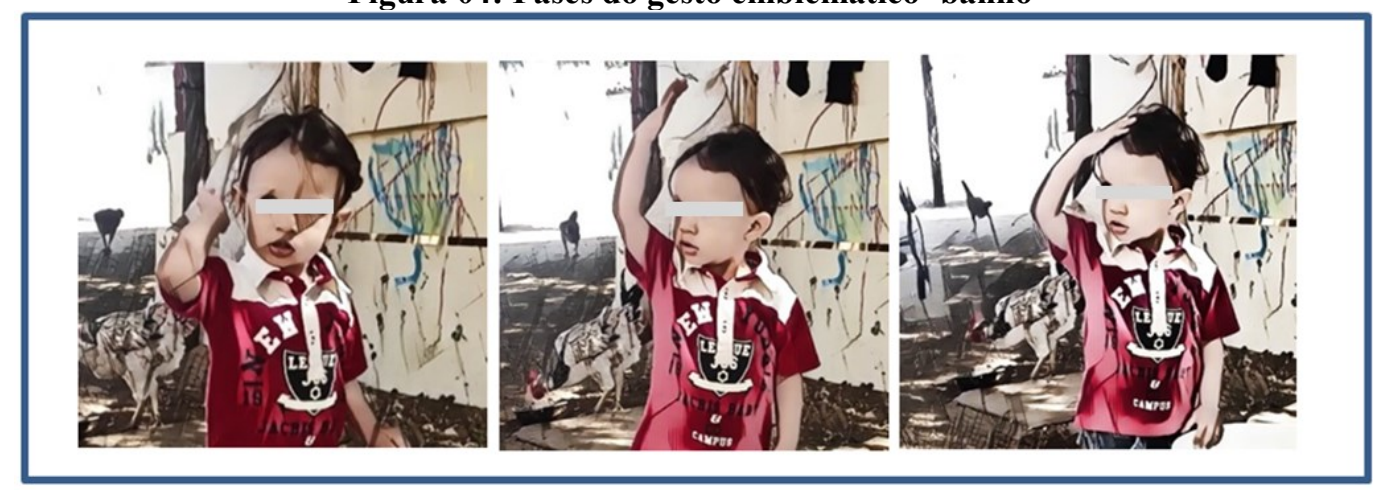

Fonte: Elaborada pelas autoras

É perceptível que o enunciado da criança é compreendido por seu par de interação, uma vez que seu interlocutor mantém o engajamento e capta, em sua totalidade, o enunciado envolvendo os três planos composicionais produzido pela criança e tem sua forma e conteúdo opacos para a pesquisadora já que não pertence à sua cultura (KITA, 2009).

Com base nos enunciados, percebemos que durante a fase de aquisição da linguagem essa criança também traz marcas não verbais, que imprimem sentidos entre as pessoas de seu contexto. Esses gestos vão sendo repassadas dos mais velhos para os mais jovens e, nesse movimento, essa criança cigana Calon vai se constituindo e se tornando um sujeito competente dentro de seu grupo. Vejamos o último extrato.

\section{Extrato 03}

Situação: Mãe e criança interagem na área externa da casa. Conforme o quadro que traz a disposição dos interactantes, nota-se que a mãe está sentada e segura o fillho no colo.

Idade da criança: 21 meses e 29 dias.

CRIANÇA \{hum:: [toca duas ou mais vezes com a palma da mão no ponto mais alto da cabeça] (olha para algo que está fora do nosso foco)

MÃE \{qué tomar banho? é?\} (olha para a criança e para algo fora do nosso foco)

CRIANÇA \{qué\} (olha para fora do foco)

MÃE

CRIANÇA

\{qué tomar banho, é? cê tá com calor (olha para a criança)

MÃE

CRIANÇA

\{é. não\} (olha para algo fora do nosso foco)

\{e por que qué tomar banho?\}

MÃE

\{choraminga\}

\{ei, tu cortou teu cabelo?\} (olha para a criança)

CRIANÇA \{ãin ãin. choraminga [toca mais de duas vezes com a palma da mão no ponto mais alto da cabeça] (olha para algo fora do nosso foco)

MÃE $\quad$ eu vô dá banho $\}$ (olha para a criança) 
Volume 14 - Número 2 - ago/dez de 2019

Figura 05: Interface do contexto interativo do extrato 02

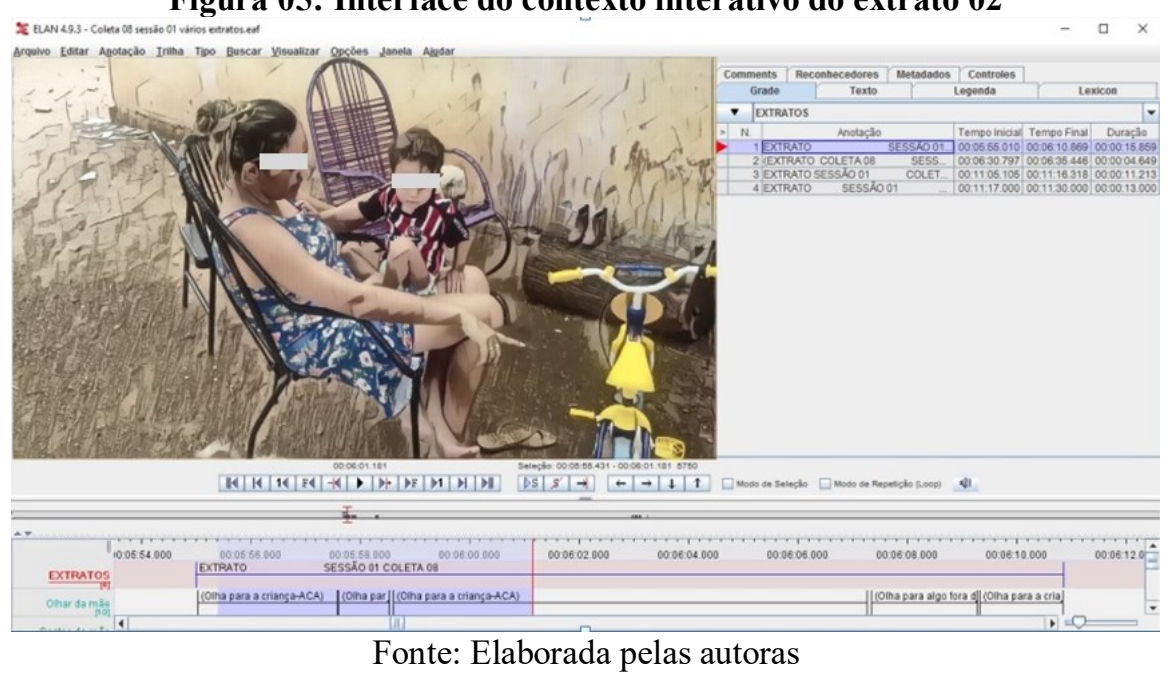

A figura 05 mostra a interface do momento de interação entre a díade mãe-criança. Novamente vemos a interação entre mãe e criança se materializando de forma multimodal. A criança inicia a interação com um enunciado através do gesto emblemático materializado ao se bater com a palma da mão na cabeça com o significado de 'banho', concomitante a produção vocal 'Humm'. A mãe se engaja na interação estabelecida pelo filho através do olhar direcionado para o filho, junto à produção vocal 'Qué tomar banho?' 'Qué tomar banho? 'É?' 'Cê tá cum calor?' 'E por que qué tomar banho?'.

Embora não haja produção vocal relacionada à palavra 'banho' no enunciado da criança, a mãe compreende o gesto emblemático realizado e se insere na dialogia, através do olhar e dos enunciados intercalados sempre pelo espaço de turno para resposta cedido entre uma produção vocal e outra à criança, que vai confirmando através da fala.

No turno 08 a mãe tenta tirar do foco da interação (evento 'banho') ao dizer: 'Ei tu cortô teu cabelo?', porém a criança choraminga e em seguida repete o mesmo gesto emblemático ao bater com a palma da mão na cabeça enquanto pronuncia 'Ãin, ãin'. A cena se encerra com o olhar da mãe direcionado para o filho ao mesmo tempo em que diz: 'Eu vô dá bãin'.

A particularidade que este último extrato apresenta é justamente esse gesto emblemático de tocar com a mão na cabeça, instaurando, assim, o sentido de 'banho'. A primeira execução veio com ausência de produção vocal e é de imediato reconhecido pela mãe, que, na cena, é quem tem mais maturidade linguística e está imersa há mais tempo na cultura cigana Calon local. De acordo com Kendon (1982), caracterizamos o gesto realizado pela criança como um emblema, convencionalizado especificamente dentro dessa cultura cigana Calon em Sousa-PB, posto que, ao que parece, não há outros estudos que discutem sobre multimodalidade em outros contextos de cultura cigana no Brasil. Na dialogia, na segunda vez que o gesto foi realizado, ele veio acompanhado da fala 'Ãin, ãin' que é um recorte da palavra 'banho' do léxico da língua portuguesa e reforçou o enunciado anterior do infante.

\section{Considerações finais}

Neste artigo, procurou-se entender como uma criança cigana se insere na língua, considerando elementos verbais e não verbais que sustentam suas interações. Pelas análises, vimos que as crianças não adquirem a língua fora de um contexto organizado social e culturalmente, o que implica pensar que aquisição da linguagem e cultura se imbricam. Assim 
Volume 14 - Número 2 - ago/dez de 2019

ficou claro que a entrada dessa criança cigana Calon na linguagem se dá no âmago do contexto cultural, no qual a criança está inserida, ressaltando uma natureza singular.

Conceber a língua como um artefato cultural dialógico e multimodal, apreendida na interação com o outro e a criança como sujeito ativo e responsivo torna-se, a nosso ver, profícuo em se tratando de uma reflexão sobre a aquisição da linguagem e constituição da identidade da criança. Ao tentar compreender a entrada de uma criança cigana Calon na linguagem, usando os pressupostos bakhtinianos e os estudos que discutem a relação gestofala, refletimos não apenas o discurso da criança em aquisição, mas também o indispensável papel do 'outro' na constituição da sua intersubjetividade através da interação composta numa matriz gesto-produção vocal, sempre de caráter ideológico.

Através dos fragmentos ilustramos como essa criança vai construindo seus enunciados, trazendo marcas verbais e não verbais cujos sentidos são compartilhados entre membros de sua cultura. Nesse sentido, a relação estabelecida entre essa criança e o 'outro' é que vai constituindo-a por meio da linguagem, num processo dialógico que está em constante construção. É no fluxo dessas interações multimodais, que percebemos alguns dos aspectos, que tornam singular a aquisição da linguagem dessa criança.

Por fim, ressaltamos que há uma 'pluralidade de culturas ciganas' e os resultados desse estudo não sugerem uma generalização das particularidades encontradas no percurso da aquisição da linguagem. Assim, esperamos que esses resultados suscitem reflexão sobre a forma de socialização da criança cigana através da linguagem, bem como a forma que apreendem e mantêm sua cultura para que sejam compreendidas, ouvidas e valorizadas em sua singularidade, sobretudo, na escola.

\section{Referências}

ÁVILA-NÓBREGA, P. V. Dialogia mãe-bebê: a emergência do envelope multimodal em contextos de atenção conjunta. Dissertação de mestrado em Linguística. Universidade Federal da Paraíba. João Pessoa-PB, 2010.

AZEVEDO, L. S.; CARDOSO, M. C. Vida de criança cigana: o brincar no seu processo de escolarização. In: Saberes in perspectiva. Jequié, v. 2, n. 4. 2012, p. 13-27.

BAKHTIN, M. M. A estilística atual e o romance. In: BAKHTIN, M. M. Teoria do romance I: A estilística. Trad. de Paulo Bezerra. São Paulo: Editora 34, 2015, p. 23-45.

BAKHTIN, M. M. Os gêneros do discurso. In: BAKHTIN, M. M. Estética da criação verbal. Trad. do russo de Paulo Bezerra. $6^{\text {a }}$ ed. São Paulo: Editora WMF Martins Fontes, 2011, p. 261-306.

BAKHTIN, M. M.; VOLOCHÍNOV, V. N. Estudo das ideologias e filosofia da linguagem. In: BAKHTIN, M. M.; VOLOCHÍNOV, V. N. Marxismo e filosofia da linguagem. Trad. de Michel Lahud e Yara Frateschi Vieira. 16. ed. São Paulo: Hucitec, 2014, p. 31-48.

Interação verbal. In: BAKHTIN, M. M.; VOLOCHÍNOV, V. N. Marxismo e

filosofia da linguagem. Tradução de Michel Lahud e Yara Frateschi Vieira. 16. ed. São Paulo: Hucitec, 2014, p. 114-132.

CALBRIS, G. The semiotics of French gestures (O. Doyle, Trans.). Bloomington \& Indianapolis: Indiana University Press (1990).

. Elements of Meaning in Gesture. John Benjamins Publishing. Philadelphia 2011.

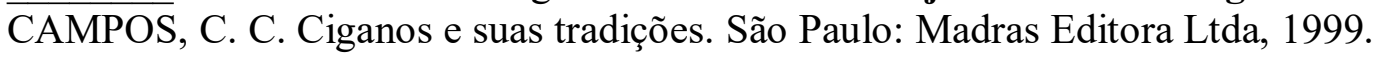

CAVALCANTE, M. C. B.; NASLAVSKY, J. P. N. A matriz inicial da subjetividade tendo como locus a dialogia do/no manhês. In: CAVALCANTE, M. C. B.; FARIA, E. M. B.; LEITÃO, M. M. Aquisição da linguagem e processamento linguístico: perspectivas teóricas e aplicadas. (Orgs.) João Pessoa: Ideia/Editora Universitária, 2011, p. 11-38. 
DEL RÉ, A.; PAULA, L.; MENDONÇA, M. C. Aquisição da linguagem e os estudos bakhtinianos do discurso. In: DEL RÉ, A.; PAULA, L.; MENDONÇA, M. C. A linguagem da criança: um olhar bakhtiniano. São Paulo: Contexto, 2014. p. 17-30.

FONSECA, I. Enterrem-me em pé: a longa viagem dos ciganos. Tradução de José Rubens Siqueira. São Paulo: Companhia das Letras, 1996.

GESSER, A. LIBRAS? que língua é essa?: crenças e preconceitos em torno da língua de sinais e da realidade surda. São Paulo: Parábola Editorial, 2009.

GOLDFARB, M. P. 1. Nômades e peregrinos: o passado como elemento identitário entre os ciganos calons na cidade de Sousa-PB. In: Cadernos de campo, São Paulo, n. 19, p. 1-384, 2010.

GOLDFARB, M. P. L. Calé: a alma do cigano. In: GOLDFARB, Maria Patrícia Lopes. Memória e etnicidade entre os ciganos em Sousa-PB. João Pessoa: Editora da UFPB, 2013. 99-123.

HOLLER, J. et al. Social eye gaze modulates processing of speech and co-speech gesture. Cognition, 133. 2014, p. 692-697.

KENDON, A. Language and gesture: unity or duality? In: McNeill, David (Edited by) Language and Gestures. Cambridge University Press. Cambridge, UK. Janeiro, 2000, p. 4763.

KITA, S. Cross-cultural variation of speech-accompanying gesture: A review. Language and Cognitive Processes, 24(2), 2009, p. 145-167.

KITA, S.; ÖZYÜREK, A. What does cross-linguistic variation in semantic coordination of speech and gesture reveal? Evidence for an interface representation of spatial thinking and speaking. Journal of Memory and Language, 48, 2003, p. 16-32.

LIMA, M. G. S. Um olhar sobre a aquisição da linguagem em criança cigana Calon. Dissertação de Mestrado. Pós-Graduação em Linguística. Universidade Federal da Paraíba. 2017.

MCNEILL, D. 1985. So you think gestures are nonverbal? Psychological Review. Vol 92(3): 350-371.

Gesture: a psycholinguistic approach. In: The Encyclopedia of Language and Linguistics. 2006, p. 1-15.

MONTEIRO, E. N. J.; GOLDFARB, M. P. L. A infância calon: notas sobre o 'ser criança' entre os ciganos no Vale do Mamanguape- Paraíba/Brasil. Fragmentos de cultura, v. 27, 2017, p.19-29.

MONTEIRO, E. N. J. As crianças calon: uma etnografia sobre a concepção de infância entre os ciganos no Vale do Mamanguape - PB. Dissertação de mestrado em Antropologia. Universidade Federal da Paraíba. 2015.

MORAES FILHO, M. Os ciganos no Brasil e o cancioneiro dos ciganos. Belo Horizonte: Ed. Itatiaia; São Paulo: Ed. da Universidade de São Paulo, 1981.

PEDERSON, E. et al. Semantic typology and spatial conceptualization. Language, 74, 1998, p. 557-589.

SILVA, F. J. O. Das tendas às telhas: A educação escolar das crianças ciganas da Praça Calon-Florânia/RN. Dissertação. Universidade Federal do Rio Grande do Norte, Natal, 2012.

SHIMURA, M. I. Identidades ciganas no Brasil. In: Anais 30 ${ }^{\boldsymbol{a}}$ Reunião Brasileira de Antropologia, João Pessoa, 2016.

SOUZA, E. N.; GOLDFARB, M. P. L. Uma perspectiva teórica sobre crianças ciganas no sertão paraibano: uma construção reflexiva a partir dos estudos de grupos ciganos na Paraíba. In: LIMA, G. J; OLIVEIRA, K. E.; CONCEIÇÃO, J. S.; TELLA, M. A. P..(Org.). Ética Antropológica em Debate: Práticas e Narrativas. 1ed. João Pessoa-PB: Ed. Universitária da UFPB, 2012, p. 314-319. 
Volume 14 - Número 2 - ago/dez de 2019

SUTHERLAND, A. Gypsies: The hidden Americans. Prospect Heights, Illinis, Waveland, 1975.

VOLOCHÍNOV, V. N. Palavra na vida e a palavra na poesia. Introdução ao problema da poética sociológica. In: VOLOCHÍNOV, V. N. A construção do enunciado e outros ensaios. Trad. De João Wanderely Geraldi. São Carlos: Pedro e João Editores, 2013, p. 71 100.

SOUZA, W. P. A.; FARIA, E. M. B. O gesto como facilitador da produção de sentido no diálogo entre crianças surdas em aquisição de linguagem. In: CAVALCANTE, M. C. B. Multimodalidade em aquisição da linguagem. João Pessoa: Editora Universitária da UFPB, 2010, p. 135-148.

TEIXEIRA, R. C. História dos ciganos no Brasil. Recife - Núcleo de Estudos Ciganos, 2008.

TOMASELLO, M. Comunicação linguística e representação simbólica. In: TOMASELLO, M. Origens culturais da aquisição do conhecimento humano. Trad. Cláudia Berliner. Martins Fontes: São Paulo, 2003, p. 131-186. 